\title{
Phase separation of borosilicate glass containing sulfur
}

\author{
Keiji SAIKI, Shinichi SAKIDA, ${ }^{*}$ Yasuhiko BENINO and Tokuro NANBA ${ }^{\dagger}$ \\ Graduate School of Environmental Science, Okayama University, 3-1-1 Tsushima-naka, Kita-ku, Okayama $700-8530$ \\ *Environmental Management Center, Okayama University, 3-1-1 Tsushima-naka, Kita-ku, Okayama 700-8530
}

\begin{abstract}
A $10 \mathrm{Na}_{2} \mathrm{~S} \cdot 30 \mathrm{~B}_{2} \mathrm{O}_{3} \cdot 60 \mathrm{SiO}_{2}(\mathrm{~mol} \%)$ glass was prepared, and the changes in glass structure and chemical state of sulfur caused by phase separation were investigated. In the as-prepared and heat-treated glasses, sulfur was present as $\mathrm{S}^{2-}$ anion and polysulfide $\mathrm{S}_{2}{ }^{-}$and $\mathrm{S}_{3}{ }^{-}$anions, and $\mathrm{Si}-\mathrm{S}$ and $\mathrm{B}-\mathrm{S}$ bonds were not confirmed. A phase separation by spinodal decomposition was observed after heat-treatment, where sulfur was preferentially distributed to borate-rich phase. Even after the phase separation, formation of non-bridging oxygen was not recognized. The preferential distribution of sulfur anions in the present glass was explainable on the basis of the change in population of sodium ions, which compensated the negatively-charged sulfur anions.
\end{abstract}

(C2010 The Ceramic Society of Japan. All rights reserved.

Key-words : Phase separation, Borosilicate glass, Chemical state of sulfur, Glass structure

[Received February 26, 2010; Accepted April 15, 2010]

\section{Introduction}

Phase separation of borosilicate glass is well known. In $\mathrm{Na}_{2} \mathrm{O}-$ $\mathrm{B}_{2} \mathrm{O}_{3}-\mathrm{SiO}_{2}$ glass, glasses with low $\mathrm{Na}_{2} \mathrm{O}$ content separate into $\mathrm{SiO}_{2}$ - and $\mathrm{B}_{2} \mathrm{O}_{3}$-rich phases due to heat-treatment at temperatures higher than glass transition temperature. ${ }^{1), 2)}$ It has been widely used in production of porous glass and $\mathrm{SiO}_{2}$ substitution. Recently, novel utilization methods of phase separation of borosilicate glass has been developed for the recycling of wastes containing $\mathrm{SiO}_{2}$, such as waste glass, ${ }^{3)}$ radioactive waste, ${ }^{4)}$ blast furnace slag5) and municipal waste slag. ${ }^{5}$ ) In the recycling process, $\mathrm{B}_{2} \mathrm{O}_{3}$ is added to the wastes, preparing borosilicate glasses, from which high $\mathrm{SiO}_{2}$ glass can be recovered by using phase separation.

In the blast furnace slag $^{5)}$ and municipal waste slag, ${ }^{6}$ ) measurable amount of sulfur $(<5 \operatorname{mass} \%)$ is included, which originate from iron ore, paper, kitchen wastes, vulcanized rubbers, etc. In recycling the sulfur-containing wastes to raw materials of glassware, sulfur should be removed from the wastes, because sulfur is a possible cause of coloration. Little is known concerning the chemical states of sulfur in borosilicate melts ${ }^{7-9)}$ and glasses. ${ }^{10), 11)}$ According to Asahi et al., ${ }^{10), 11)}$ sulfurs in $\mathrm{Na}_{2} \mathrm{~S}-\mathrm{B}_{2} \mathrm{O}_{3}-\mathrm{SiO}_{2}$ glass are present with a negative charge in the glass, and $\mathrm{Si}-\mathrm{S}$ bonds are confirmed only when non-bridging oxygen (NBO) atoms are formed in the glasses.

To the knowledge of the authors, no report has been published on the phase separation of sulfur-containing glasses. Then, in the present study, phase separation of a glass in $\mathrm{Na}_{2} \mathrm{~S}-\mathrm{B}_{2} \mathrm{O}_{3}-\mathrm{SiO}_{2}$ system has been investigated. Sulfur-containing $10 \mathrm{Na}_{2} \mathrm{~S} \cdot 30 \mathrm{~B}_{2} \mathrm{O}_{3}$. $60 \mathrm{SiO}_{2}$ glass $(\mathrm{mol} \%)$ and sulfur-free $10 \mathrm{Na}_{2} \mathrm{~S} \cdot 30 \mathrm{~B}_{2} \mathrm{O}_{3} \cdot 60 \mathrm{SiO}_{2}$ glass for comparison were prepared. The glass composition was chosen because of the similarity with Vycor $^{\circledR}$ glass. Chemical state of sulfur in the sulfur-containing glass was investigated from optical absorption, and chemical composition was determined with inductively-coupled plasma (ICP) emission spectrometry. Glass structure was examined with using ${ }^{11} \mathrm{~B}$ and ${ }^{29} \mathrm{Si}$ MAS-NMR spectrometries. Texture after phase separation

\footnotetext{
Corresponding author: T. Nanba; E-mail: tokuro_n@cc.okayamau.ac.jp
}

was observed with scanning electron microscope (SEM). From these analyses, changes in glass structure and chemical states of sulfur caused by phase separation were studied.

\section{Experimental}

The glasses with compositions given in Table 1 were prepared by a conventional melt-quenching method. The raw materials of reagent grade $\mathrm{Na}_{2} \mathrm{~S}, \mathrm{Na}_{2} \mathrm{CO}_{3}, \mathrm{~B}_{2} \mathrm{O}_{3}$ and $\mathrm{SiO}_{2}$ were mixed thoroughly and melted in an alumina crucible with a lid of alumina placed in an electric furnace at $1400^{\circ} \mathrm{C}$ for $30 \mathrm{~min}$. In preparing the sulfur-free glass, a platinum crucible with a lid of alumina was used. The melts were poured onto an iron plate and quenched by being pressed with another iron plate to form glass plates with a thickness of $2-3 \mathrm{~mm}$. Differential thermal analyses (DTA) were carried out with a heating rate of $10 \mathrm{~K} / \mathrm{min}$ in order to determine glass transition and crystallization temperatures, $T_{\mathrm{g}}$ and $T_{\mathrm{x}}$, respectively.

Heat treatments for phase separation were performed at the temperatures 600 and $650^{\circ} \mathrm{C}$, which were between $T_{\mathrm{g}}$ and $T_{\mathrm{x}}$. After the heat treatment, the glasses were immersed in nitric acid of $1.0 \mathrm{~N}$ for 16 and $48 \mathrm{~h}$, and the insoluble residues were recovered with vacuum filtration. After being rinsed in water and dried in an oven, silica-rich glasses were obtained.

$\mathrm{X}$-ray diffraction (XRD) measurement was done to confirm the

Table 1. Batch and ICP analytical compositions of the samples

\begin{tabular}{lcclccc}
\hline & \multicolumn{2}{c}{$10 \mathrm{Na}_{2} \mathrm{~S} \cdot 30 \mathrm{~B}_{2} \mathrm{O}_{3} \cdot 60 \mathrm{SiO}_{2}$} & & \multicolumn{2}{c}{$10 \mathrm{Na}_{2} \mathrm{O} \cdot 30 \mathrm{~B}_{2} \mathrm{O}_{3} \cdot 60 \mathrm{SiO}_{2}$} \\
\cline { 2 - 3 } \cline { 6 - 7 } Component & $\begin{array}{c}\text { Batch/ } \\
\text { mol \% }\end{array}$ & $\begin{array}{c}\text { Analytical/ } \\
\text { mol \% }\end{array}$ & & $\begin{array}{c}\text { Batch/ } \\
\text { mol \% }\end{array}$ & $\begin{array}{c}\text { Analytical/ } \\
\text { mol \% }\end{array}$ \\
\hline $\mathrm{Na}_{2} \mathrm{~S}$ & 10.0 & $6.8^{* 1}\left(3.2^{* 2}\right)$ & & - & - \\
$\mathrm{Na}_{2} \mathrm{O}$ & - & $0.3^{* 1}\left(3.9^{* 2}\right)$ & & 10.0 & 8.4 \\
$\mathrm{~B}_{2} \mathrm{O}_{3}$ & 30.0 & 27.7 & & 30.0 & 28.8 \\
$\mathrm{SiO}_{2}$ & 60.0 & 65.2 & & 60.0 & 62.8 \\
$\mathrm{Al}_{2} \mathrm{O}_{3}{ }^{*}$ & - & $2.0^{* 3}$ & & - & - \\
\hline
\end{tabular}

*1: Tentative content under the assumption that sulfurs are present as an $\mathrm{S}^{2-}$ anionic state.

${ }^{*}$ 2: Final content estimated from the results of ${ }^{11} \mathrm{~B}$ MAS-NMR. The average charge of $\mathrm{S}$ is estimated as -0.94 .

*3: External content. 


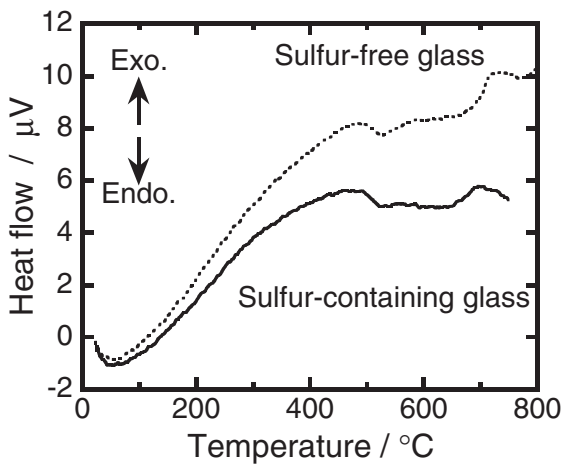

Fig. 1. DTA curves of the as-prepared glasses.

specimens remaining in amorphous state. Chemical composition of the specimens, such as the glasses before phase separation and the acidic solutions and insoluble residues after acid treatment was determined by an inductively coupled plasma (ICP) emission spectrometry. Optical absorption was evaluated by a spectrophotometer with a wavelength range of $250-750 \mathrm{~nm}$, and the diffuse reflection measurement was applied for the specimens after acid treatment. Phase separation was confirmed by a scanning electron microscope (SEM) observation, where the specimens were etched in 5\% HF solution for $60 \mathrm{~s}$. Local structures around $\mathrm{Si}$, $\mathrm{B}$ and $\mathrm{Al}$ atoms were investigated with ${ }^{29} \mathrm{Si},{ }^{11} \mathrm{~B}$ and ${ }^{27} \mathrm{Al}$ MASNMR measurements, respectively. For the ${ }^{29} \mathrm{Si}$ MAS-NMR measurement, $0.2 \mathrm{~mol} \%$ of $\mathrm{Gd}_{2} \mathrm{O}_{3}$ was added to the glass batches in order to shorten the relaxation time. NMR measurements were carried out at $7.05 \mathrm{~T}$ on a Varian Unity Inova 300 spectrometer, and the respective conditions of ${ }^{29} \mathrm{Si},{ }^{11} \mathrm{~B}$ and ${ }^{27} \mathrm{AlNMR}$ measurements were as follows: frequency $=59.6$, 96.2 and $78.2 \mathrm{MHz}$, sample spinning speed $=5.0 \mathrm{kHz}$ (all), pulse duration $=4.0,0.6$ and $0.6 \mu \mathrm{s}$, repetition time $=1.0 \mathrm{~s}$ (all), chemical shift standard = poly (dimethyl siloxane) (PDMS), $\mathrm{BPO}_{4}$ and aq. $\mathrm{AlCl}_{3}$.

\section{Results}

\subsection{As-prepared glasses}

The analytical composition of the glasses is shown in Table 1, in which $\mathrm{Na}_{2} \mathrm{~S}$ and $\mathrm{Na}_{2} \mathrm{O}$ contents $\left({ }^{*} 1\right.$ in Table 1$)$ are tentatively given based on the assumption that sulfurs are present as an $\mathrm{S}^{2-}$ anionic state. In both glasses, $\mathrm{SiO}_{2}$ content increases as compared with the nominal compositions, indicating that parts of $\mathrm{Na}_{2} \mathrm{~S}$, $\mathrm{Na}_{2} \mathrm{O}$ and $\mathrm{B}_{2} \mathrm{O}_{3}$ were volatilized during the melting process. In the sulfur-containing glass, $\mathrm{Al}$ is also confirmed, which is eluted from the alumina crucible used. The remaining rate of sulfur in the as-prepared glass is estimated at $63 \%$. Figure 1 shows the DTA curves of the as-prepared glasses. $T_{\mathrm{g}}$ and $T_{\mathrm{x}}$ of the sulfurcontaining as-prepared glass are 473 and $657^{\circ} \mathrm{C}$, respectively, and those of the sulfur-free glass are 486 and $672^{\circ} \mathrm{C}$. The difference in $T_{\mathrm{g}}$ and $T_{\mathrm{x}}$ between the glasses are not so clear, and the difference in coloration is, however, quite clear.

As shown in Fig. 2, the sulfur-containing glass is faint blue, and the sulfur-free glass is colorless. In the optical transmission spectra shown in Fig. 3, the sulfur-containing glass shows lower transmittance at $\lambda>300 \mathrm{~nm}$ than the sulfur-free glass, and a strong and weak absorptions are confirmed at 585 and $400 \mathrm{~nm}$, which are attributed to $\mathrm{S}_{3}{ }^{-}$and $\mathrm{S}_{2}{ }^{-}$, respectively. ${ }^{12)}$ According to Asahi et al., 10),11) low-molecular-weight sulfur anions such as $\mathrm{S}_{2}{ }^{-}, \mathrm{S}_{3}{ }^{-}$and $\mathrm{S}^{2-}$ are present in the space between the glass networks without forming $\mathrm{Si}-\mathrm{S}$ and $\mathrm{B}-\mathrm{S}$ bonds in the case of low alkali glasses colored faint blue or blue, and in the case of high (a)

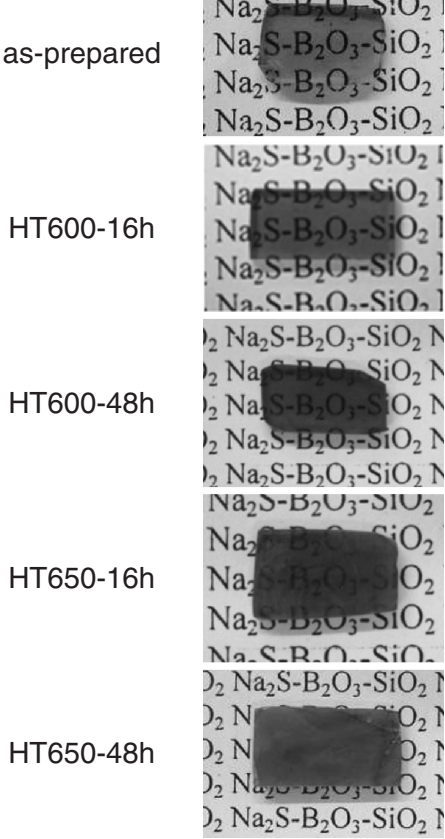

(b)

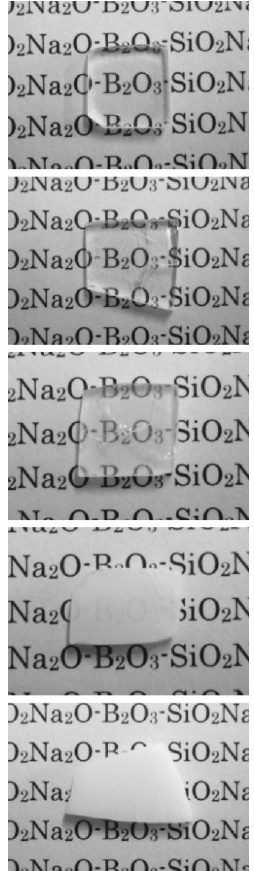

Fig. 2. Photographs of the glasses before and after the heat-treatment (a) $10 \mathrm{Na}_{2} \mathrm{~S} \cdot 30 \mathrm{~B}_{2} \mathrm{O}_{3} \cdot 60 \mathrm{SiO}_{2}$, (b) $10 \mathrm{Na}_{2} \mathrm{O} \cdot 30 \mathrm{~B}_{2} \mathrm{O}_{3} \cdot 60 \mathrm{SiO}_{2}$.
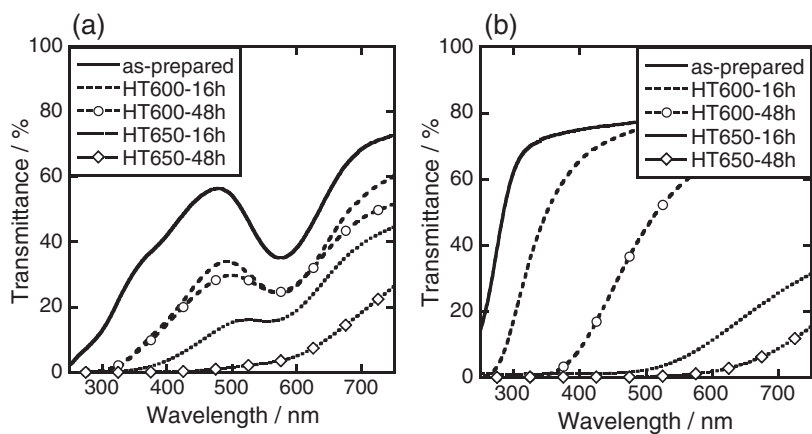

Fig. 3. Transmittance spectra of the glasses before and after the heattreatment. (a) $10 \mathrm{Na}_{2} \mathrm{~S} \cdot 30 \mathrm{~B}_{2} \mathrm{O}_{3} \cdot 60 \mathrm{SiO}_{2}$, (b) $10 \mathrm{Na}_{2} \mathrm{O} \cdot 30 \mathrm{~B}_{2} \mathrm{O}_{3} \cdot 60 \mathrm{SiO}_{2}$.

alkali glasses colored yellow or red, $\mathrm{S}^{2-}$ anions are substituted for $\mathrm{NBO}$ ions in $\mathrm{SiO}_{4}$ and $\mathrm{BO}_{3}$ units at the end of the glass networks, and polysulfide anions $\mathrm{S}_{x}{ }^{2-}$ with larger size are also present in the space between the glass networks. It is well known in borosilicate glass that NBOs are not produced in the glasses with $\mathrm{Na}_{2} \mathrm{O} / \mathrm{B}_{2} \mathrm{O}_{3}$ molar ratio $<0.5{ }^{13)}$ In the present glasses, $\mathrm{Na}_{2} \mathrm{~S}\left(\mathrm{Na}_{2} \mathrm{O}\right) / \mathrm{B}_{2} \mathrm{O}_{3}$.ratio is small $(\approx 1 / 3)$, and hence NBOs are expected to be absent. It is consequently suggested that the coloration of faint blue is due to the optical absorption at $585 \mathrm{~nm}$ of $\mathrm{S}_{3}{ }^{-}$anions present in the space between the glass networks. As indicated, $\mathrm{S}_{3}^{-}$and $\mathrm{S}_{2}{ }^{-}$anions other than $\mathrm{S}^{2-}$ anions are confirmed in the as-prepared glasses, and hence the average charge of sulfur anions should be less negative than -2 . The chemical states of sulfur will be discussed later.

Figure 4 shows ${ }^{29} \mathrm{Si}$ MAS-NMR spectra. In the as-prepared glasses, a peak at $\delta \approx-105 \mathrm{ppm}$ is commonly observed, which is assigned to $\mathrm{Q}_{4}$ species, that is, $\mathrm{SiO}_{4}$ unit consisting of four bridging oxygen (BO) atoms. If $\mathrm{Si}-\mathrm{S}$ bonds were present, peaks would be observed at around -20 and $-60 \mathrm{ppm} .{ }^{14)}$ In the present glass, however, these peaks are not recognized in Fig. 4a, 
(a)
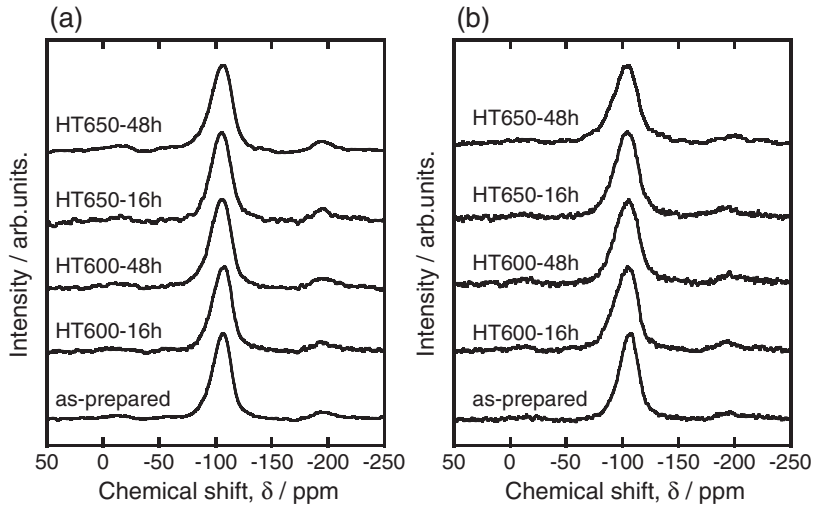

Fig. 4. ${ }^{29} \mathrm{Si}$ MAS-NMR spectra of the glasses before and after the heattreatment. (a) $10 \mathrm{Na}_{2} \mathrm{~S} \cdot 30 \mathrm{~B}_{2} \mathrm{O}_{3} \cdot 60 \mathrm{SiO}_{2}$, (b) $10 \mathrm{Na}_{2} \mathrm{O} \cdot 30 \mathrm{~B}_{2} \mathrm{O}_{3} \cdot 60 \mathrm{SiO}_{2}$. (a)

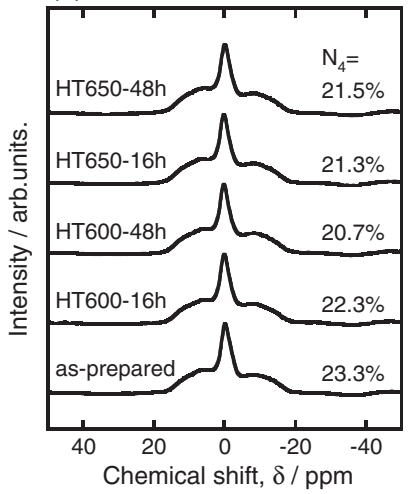

(b)

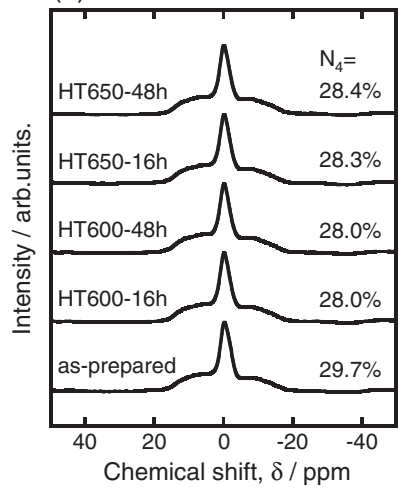

Fig. 5. ${ }^{11} \mathrm{~B}$ MAS-NMR spectra of the glasses before and after the heattreatment. (a) $10 \mathrm{Na}_{2} \mathrm{~S} \cdot 30 \mathrm{~B}_{2} \mathrm{O}_{3} \cdot 60 \mathrm{SiO}_{2}$, (b) $10 \mathrm{Na}_{2} \mathrm{O} \cdot 30 \mathrm{~B}_{2} \mathrm{O}_{3} \cdot 60 \mathrm{SiO}_{2}$.

suggesting that sulfur atoms are not bound to $\mathrm{Si}$ atoms and present in the space between the glass networks.

The result of ${ }^{11}$ B MAS-NMR measurement is shown in Fig. 5. The sharp peak at $\delta \approx 0 \mathrm{ppm}$ and the asymmetric broad peak at $20--20 \mathrm{ppm}$ are associated with four- and three-coordinated boron (B4 and B3) atoms, respectively. The relative amount of B4 with respect to total amount of boron is designated as $N_{4} \equiv$ $\mathrm{B} 4 /(\mathrm{B} 3+\mathrm{B} 4)$, which is estimated from the peak separation of ${ }^{11}$ B MAS-NMR spectrum. Comparing the as-prepared glasses, the sulfur-containing glass shows smaller $N_{4}$ value than the sulfur-free glass. As shown in Table 1, the incorporation of $\mathrm{Al}$ from the $\mathrm{Al}$ crucible used is confirmed. $\mathrm{Al}$ atoms in the sulfurcontaining glass are present in tetrahedral $\mathrm{AlO}_{4}$ units, which is identified from ${ }^{27} \mathrm{Al}$ MAS-NMR measurement. It is well known that tetrahedral $\mathrm{AlO}_{4}$ units take part in glass networks, and $\mathrm{AlO}_{4}$ units possess a negative charge so that network modifiers such as $\mathrm{Na}^{+}$ions are consumed to compensate the negative charge of $\mathrm{AlO}_{4}$ units. $\mathrm{Na}^{+}$ions are also used for the compensation of sulfur anions present in the space between the glass networks, and hence the amount of remaining $\mathrm{Na}^{+}$ions in the sulfur-containing glass is less than that in the sulfur-free glass. That is the reason for the difference in $N_{4}$ value between the sulfur-containing and sulfur-free glasses.

\subsection{Changes due to heat treatment}

As shown in Fig. 1, $T_{\mathrm{g}}$ and $T_{\mathrm{x}}$ of the as-prepared glasses were not so different regardless of sulfur. Thereby, the heat-treatment temperatures were chosen at 600 and $650^{\circ} \mathrm{C}$. As shown in Figs. 2 (a)

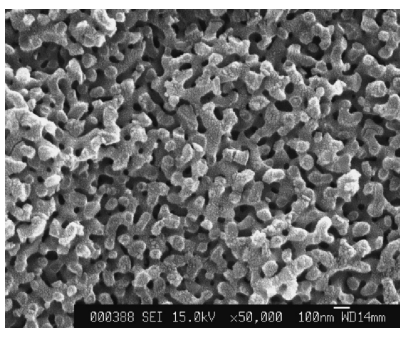

(b)

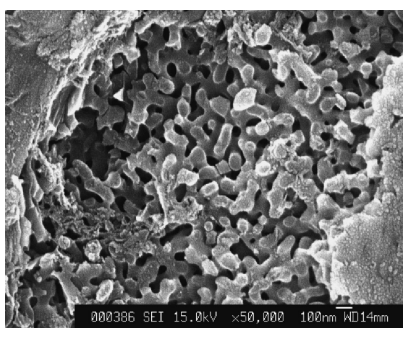

Fig. 6. SEM photographs of the glass surfaces heated at $600^{\circ} \mathrm{C}$ for $48 \mathrm{~h}$. (a) $10 \mathrm{Na}_{2} \mathrm{~S} \cdot 30 \mathrm{~B}_{2} \mathrm{O}_{3} \cdot 60 \mathrm{SiO}_{2}$, (b) $10 \mathrm{Na}_{2} \mathrm{O} \cdot 30 \mathrm{~B}_{2} \mathrm{O}_{3} \cdot 60 \mathrm{SiO}_{2}$.

and 3, the heat-treatments result in the changes of the appearance and optical transmittance of the glasses. The sulfur-containing glass turns murky blue, and the sulfur-free glass becomes translucent white, and the decrease in optical transmission is observed in UV to visible region. It was confirmed from XRD measurement that all the samples remained in amorphous state after the heat treatments. It is therefore suggested that the decrease in optical transmission is caused by the phase separation in the glasses, and it is also expected that the size of the separated phases is comparable with the wavelength of the scattered light.

Figure 6 shows the SEM photographs of the surface of the heat-treated samples. Regardless of sulfur, spinodal phase separation is commonly confirmed in the heat-treated glasses. The size of the phase-separated texture is ca. $200 \mathrm{~nm}$, and there is little difference between the sulfur-containing and sulfur-free glasses.

After the heat-treatments, ${ }^{29} \mathrm{Si} \mathrm{NMR} \mathrm{peak} \mathrm{is} \mathrm{broadened} \mathrm{slightly}$ to lower magnetic field side, and another peak component is confirmed at around $-90 \mathrm{ppm}$ (Fig. 4). In Si NMR spectra of alkali silicate glasses, ${ }^{15)}$ peaks at $-85--92 \mathrm{ppm}$ are attributed to $\mathrm{Q}_{3}$ species $\left(\mathrm{SiO}_{4}\right.$ unit consisting of three $\mathrm{BOs}$ and one $\left.\mathrm{NBO}\right)$. In the present glasses, however, absence of NBO is expected from the glass composition even after the heat-treatments. It is consequently concluded that the $-90 \mathrm{ppm}$ peak is attributable to $\mathrm{Q}_{4}$ species neighboring of tetrahedral $\mathrm{BO}_{4}$ units. ${ }^{16), 17)}$ As described below, most $\mathrm{Si}$ atoms are present in $\mathrm{SiO}_{2}$-rich phase after the phase separation, and little $\mathrm{B}$ atoms are present in the $\mathrm{SiO}_{2}$-rich phase. It is thereby supposed that the $-90 \mathrm{ppm}$ peak is not derived from $\mathrm{Si}$ atoms in the $\mathrm{SiO}_{2}$-rich phase. However, little $\mathrm{Si}$ atoms should be distributed to the $\mathrm{B}_{2} \mathrm{O}_{3}$-rich phase, and it is therefore supposed that the contribution of $\mathrm{Si}$ atoms in the $\mathrm{B}_{2} \mathrm{O}_{3}$ rich phase giving the $-90 \mathrm{ppm}$ peak is emphasized for some reason. $\mathrm{Gd}_{2} \mathrm{O}_{3}$ was added to the glass batches for the ${ }^{29} \mathrm{Si}$ MAS$\mathrm{NMR}$ measurement. If more $\mathrm{Gd}$ atoms are distributed to the $\mathrm{B}_{2} \mathrm{O}_{3}$-rich phase after the phase separation, relative intensity of the $-90 \mathrm{ppm}$ peak will be enhanced than the case of even distribution of $\mathrm{Gd}$ atoms.

As shown in ${ }^{11}$ B MAS-NMR spectra (Fig. 5), $N_{4}$ value decreases slightly after the heat-treatments regardless of sulfur in the glasses. According to Dell et al., ${ }^{13)} N_{4}$ value is dependent only on $\mathrm{Na}_{2} \mathrm{O} / \mathrm{B}_{2} \mathrm{O}_{3}$ molar ratio in the NBO-free glasses such as $\mathrm{Na}_{2} \mathrm{O} / \mathrm{B}_{2} \mathrm{O}_{3}<0.5$. In the present sulfur-free glass, $\mathrm{Na}_{2} \mathrm{O} / \mathrm{B}_{2} \mathrm{O}_{3}$ ratio is almost constant at $1 / 3$ even after phase separation, and hence $N_{4}$ value should not change. The reason for the change in $N_{4}$ value is discussed later.

\subsection{Changes due to acid treatment}

The chemical composition of the glass phases after the phase separation was estimated as follows; the $\mathrm{B}_{2} \mathrm{O}_{3}$-rich phase is 
Table 2. ICP analytical composition of the glass phases after the heattreatment at $650^{\circ} \mathrm{C}$ for $16 \mathrm{~h}$

\begin{tabular}{ccc}
\hline Component & $\mathrm{SiO}_{2}$-rich phase $/ \mathrm{mol} \%$ & $\mathrm{~B}_{2} \mathrm{O}_{3}$-rich phase $/ \mathrm{mol} \%$ \\
\hline $\mathrm{Na}_{2} \mathrm{~S}$ & 0 & $18.9^{* 1}\left(3.6^{* 2}\right)$ \\
$\mathrm{Na}_{2} \mathrm{O}$ & 0.1 & $3.2^{* 1}\left(18.5^{* 2}\right)$ \\
$\mathrm{B}_{2} \mathrm{O}_{3}$ & 3.0 & 76.9 \\
$\mathrm{SiO}_{2}$ & 96.9 & 1.0 \\
$\mathrm{Al}_{2} \mathrm{O}_{3}{ }^{*}$ & 0.3 & $2.1^{* 3}$ \\
\hline
\end{tabular}

*1: Tentative content under the assumption that sulfurs are present as an $\mathrm{S}^{2-}$ anionic state.

${ }^{*}$ 2: Final content estimated from the results of ${ }^{11}$ B MAS-NMR. The average charge of $\mathrm{S}$ is estimated as -0.38 .

*3: External content.

soluble to $\mathrm{HNO}_{3}$ solution, and hence the composition of the $\mathrm{B}_{2} \mathrm{O}_{3}$-rich phase was determined from the concentration of the elements in the acid solution after the acid-treatment. The $\mathrm{SiO}_{2}-$ rich phase is insoluble to $\mathrm{HNO}_{3}$ solution but is soluble to $\mathrm{HF}$ solution, and hence the insoluble solids obtained after immersing $\mathrm{HNO}_{3}$ solution were completely dissolved by HF solution, from which the composition of the $\mathrm{SiO}_{2}$-rich phase was determined. The result for the glass heat-treated at $650^{\circ} \mathrm{C}$ for $16 \mathrm{~h}$ is shown in Table 2. Sulfur is completely eluted to $\mathrm{HNO}_{3}$ solution, indicating that sulfur is preferentially introduced to the $\mathrm{B}_{2} \mathrm{O}_{3}$-rich phase during the phase separation.

Figure 7 shows the optical absorption spectra, in which the photograph of a specimen after acid-treatment is also shown. The specimen after acid-treatment is porous and opaque, and hence diffuse reflectance measurement was used to obtain the absorption spectra shown in Fig. 7. The peaks at 585 and $400 \mathrm{~nm}$ associated with $\mathrm{S}_{3}{ }^{-}$and $\mathrm{S}_{2}{ }^{-}$, respectively, are not observed after acid-treatment, which is consistent with the composition analyses.

\section{Discussion}

\subsection{Glass composition and chemical states of sulfur}

As shown in Fig. 5, the fraction of four-fold coordinated boron atoms, $N_{4}$ in the sulfur-containing glass is less than that in the sulfur-free glass. In the sulfur-containing glass, sulfur anions and $\mathrm{AlO}_{4}$ units are present, and $\mathrm{Na}^{+}$ions are consumed to compensate the negative charge of these negative species. Tetrahedral $\mathrm{BO}_{4}$ units also possess a negative charge, and equivalent amount of $\mathrm{Na}^{+}$ions are required for charge compensation. According to Dell et al., ${ }^{13)} N_{4}$ value is predicted as $N_{4}=\mathrm{Na}_{2} \mathrm{O} / \mathrm{B}_{2} \mathrm{O}_{3}$ molar ratio in the NBO-free borate and borosilicate glasses. $N_{4}$ value of the sulfur-containing as-prepared glass is $23.3 \%$, and the amount of $\mathrm{Na}_{2} \mathrm{O}$ used to produce $\mathrm{BO}_{4}$ units is therefore expected as $6.5 \mathrm{~mol} \%$. In addition, $2 \mathrm{~mol} \%$ of $\mathrm{Na}_{2} \mathrm{O}$ is required to form $\mathrm{AlO}_{4}$ units, and total amount of $\mathrm{Na}_{2} \mathrm{O}$ consumed for the $\mathrm{BO}_{4}$ and $\mathrm{AlO}_{4}$ units is $8.5 \mathrm{~mol} \%$. However, the analytical amount of $\mathrm{Na}_{2} \mathrm{~S}+\mathrm{Na}_{2} \mathrm{O}$ is only $7.1 \mathrm{~mol} \%$, which is insufficient to compensate the negatively-charged species.

According to Nanba et al., ${ }^{18)}$ the fraction of four-fold coordinated boron atoms in borosilicate glass is predicted based on the optical basicity, $\Lambda$, which is calculated from glass composition and electronegativity of the glass constituents. Based on their prediction, $1.9 \mathrm{~mol} \%$ of $\mathrm{Na}_{2} \mathrm{O}$ is enough to obtain $N_{4}=23.3 \%$ for the glass at $\mathrm{B}_{2} \mathrm{O}_{3}: \mathrm{SiO}_{2}=27.7: 65.2$. Then, 1.9 and $2.0 \mathrm{~mol} \%$ of $\mathrm{Na}_{2} \mathrm{O}$ is consumed to form $\mathrm{BO}_{4}$ and $\mathrm{AlO}_{4}$ units, respectively. Consequently, $3.2 \times 2 \mathrm{~mol} \%$ of $\mathrm{Na}^{+}$ions is remaining to compensate $6.8 \mathrm{~mol} \%$ of negatively-charged sulfur

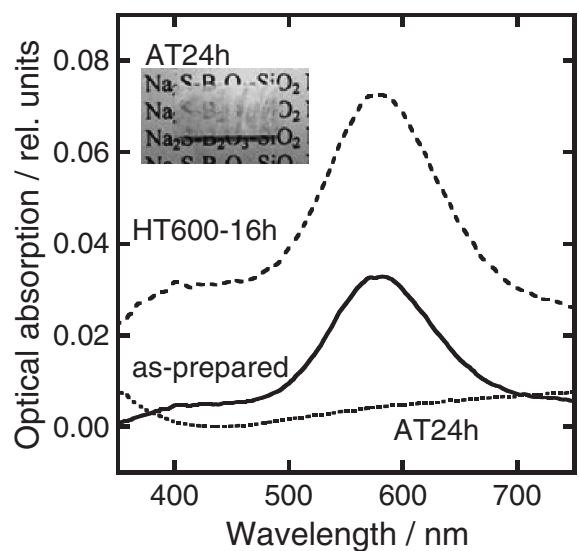

Fig. 7. Optical absorption spectra obtained from diffuse reflectance measurements of $10 \mathrm{Na}_{2} \mathrm{~S} \cdot 30 \mathrm{~B}_{2} \mathrm{O}_{3} \cdot 60 \mathrm{SiO}_{2}$ glass before and after the heatand acid-treatments. The inset indicates the specimen after acid-treatment.

atoms, and the average charge of sulfur anions is thereby estimated at -0.94 . The composition of the sulfur-containing asprepared glass is finally given as $3.2 \mathrm{Na}_{2} \mathrm{~S}_{2.13} \cdot 3.9 \mathrm{Na}_{2} \mathrm{O} \cdot 27.7 \mathrm{~B}_{2} \mathrm{O}_{3}$. $65.2 \mathrm{SiO}_{2}+2.0 \mathrm{Al}_{2} \mathrm{O}_{3}$.

The composition of the $\mathrm{B}_{2} \mathrm{O}_{3}$-rich phase in the sulfurcontaining glass after a heat-treatment $\left(650^{\circ} \mathrm{C}-16 \mathrm{~h}\right)$ is also estimated in the same way, resulting in $3.6 \mathrm{Na}_{2} \mathrm{~S}_{5.25} \cdot 18.5 \mathrm{Na}_{2} \mathrm{O}$. $76.9 \mathrm{~B}_{2} \mathrm{O}_{3} \cdot 1.0 \mathrm{SiO}_{2}+2.1 \mathrm{Al}_{2} \mathrm{O}_{3}$. The average charge of sulfur anions after the heat-treatment is estimated at -0.38 , which is much less than the charge of -0.94 before the heat-treatment. As shown in Fig. 7, the absorption peaks at 585 and $400 \mathrm{~nm}$ increase in intensity due to the heat-treatment, indicating the increase in the polysulfide anions of $\mathrm{S}_{3}{ }^{-}$and $\mathrm{S}_{2}{ }^{-}$, that is, the polymerization of $\mathrm{S}^{2-}$ anions. After the heat treatment, the elimination of sulfur is not confirmed from ICP analysis, which also indicates the polymerization of sulfur anions or the increase of zero-valence molecular sulfurs such as $\mathrm{S}_{2}$.

At phase separation, sulfurs and $\mathrm{Al}_{2} \mathrm{O}_{3}$ are selectively incorporated in $\mathrm{B}_{2} \mathrm{O}_{3}$-rich phase, which is explainable by the distribution of $\mathrm{Na}^{+}$ions. In the present glass, sulfurs are present as anions, such as $\mathrm{S}^{2-}$ and polymerized $\mathrm{S}_{2}{ }^{-}$and $\mathrm{S}_{3}-$ polysulfides. These negatively-charged sulfide anions are associated with $\mathrm{Na}^{+}$ ions as a charge compensator. $\mathrm{Na}^{+}$ions also compensate negatively-charged $\mathrm{BO}_{4}$ and $\mathrm{AlO}_{4}$ units. At phase separation, $\mathrm{Na}^{+}$ ions are preferentially distributed to $\mathrm{B}_{2} \mathrm{O}_{3}$-rich phase, and the distribution shift of $\mathrm{Na}^{+}$ions to $\mathrm{B}_{2} \mathrm{O}_{3}$-rich phase is accompanied by the segregation of negatively-charged species, resulting in the condensation of sulfurs and $\mathrm{Al}_{2} \mathrm{O}_{3}$ into $\mathrm{B}_{2} \mathrm{O}_{3}$-rich phase.

\subsection{Fraction of $\mathrm{BO}_{4}$ units}

As shown in Fig. 5, the $N_{4}$ value decreases slightly after the heat-treatment regardless of sulfur in the glasses. As above mentioned, no NBOs are formed in the present glasses even after the heat-treatment, and hence the decrease in $N_{4}$ value is not explainable by the formation of NBOs. In borosilicate glass, Chen et al. ${ }^{19)}$ reported the change in $N_{4}$ after heat-treatment, where they claimed that phase separation, formation of NBO and structural rearrangement of borate groups were responsible for the change in $N_{4}$. In the present glass, however, NBOs are not formed after the phase separation, and hence the total amount of $\mathrm{BO}_{4}$ units should be kept even after the structural rearrangement.

As above mentioned, Nanba et al. ${ }^{18)}$ reported the prediction of $\mathrm{BO}_{4}$ fraction, in which it was revealed that $N_{4}$ value increased with increasing $\mathrm{SiO}_{2} / \mathrm{B}_{2} \mathrm{O}_{3}$ molar ratio. Before phase separation, 
$\mathrm{SiO}_{2} / \mathrm{B}_{2} \mathrm{O}_{3}$ ratio is $\sim 60 / 30=2.0$, and after phase separation, $\mathrm{SiO}_{2} / \mathrm{B}_{2} \mathrm{O}_{3}$ ratio in $\mathrm{B}_{2} \mathrm{O}_{3}$-rich phase decreases to almost nothing $(1.0 / 76.9=0.01$ from Table 2$)$. It is consequently concluded that the difference in $N_{4}$ between as-prepared and heat-treated glasses is responsible for the change in composition from borosilicate to borate glasses.

\section{Conclusion}

Ternary $\mathrm{Na}_{2} \mathrm{~S}-\mathrm{B}_{2} \mathrm{O}_{3}-\mathrm{SiO}_{2}$ glasses were prepared by a conventional melt-quenching method, and the distribution behavior of sulfurs due to phase separation was investigated. After heattreatment, the decrease in optical transmission was observed, and a spinodal phase separation was confirmed from SEM observation. ${ }^{29} \mathrm{Si}$ MAS-NMR spectra suggested that $\mathrm{Si}$ atoms were present in $\mathrm{Q}_{4}$ species, and $\mathrm{Si}-\mathrm{S}$ and $\mathrm{Si}-\mathrm{NBO}$ bonds were not produced in the glasses even after the phase separation. It was also indicated that sulfurs were present in the space between the glass networks as anions, such as $\mathrm{S}^{2-}$ and polymerized $\mathrm{S}_{2}{ }^{-}$and $\mathrm{S}_{3}{ }^{-}$polysulfides. $\mathrm{Na}^{+}$ions were consumed to compensate the sulfur anions, and hence the fraction of $\mathrm{BO}_{4}$ units in the sulfurcontaining glasses was smaller than that in the sulfur-free glasses. After acid-treatment, absence of sulfur was confirmed in the insoluble solids, and the optical absorption of polysulfides also disappeared. The distribution behavior of sulfurs was successfully explained by the population shift of $\mathrm{Na}^{+}$ions.

Acknowledgment The authors acknowledge helpful comments and suggestions by Dr. Taro Asahi of Niihama National College of Technology. They also thank Dr. Masahiro Nagae of Research Institute for Applied Sciences and Prof. Michihiro Miyake of Okayama University for the experimental support of SEM observation.

\section{References}

1) R. J. Charles and F. E. Wagstaff, J. Am. Ceram. Soc., 51, 16-20 (1968).
2) W. Haller, D. H. Blackburn, F. E. Wagstaff and R. J. Charles, J. Am. Ceram. Soc., 53, 34-38 (1970).

3) T. Akai, D. Chen, H. Masui, K. Kuraoka and T. Yazawa, "Method for recycling waste glass and recycled glass," International Patent No. WO/2003/024879 (2003).

4) K. Uruga, K. Doka, K. Sawada, Y. Enokida and I. Yamamoto, J. Nucl. Sci. Technol., 45, 889-898 (2008).

5) T. Nanba, S. Mikami, T. Imaoka, S. Sakida and Y. Miura, J. Ceram. Soc. Japan, 116, 220-223 (2008).

6) T. Nanba, Y. Kuroda, S. Sakida and Y. Benino, J. Ceram. Soc. Japan, 117, 1195-1198 (2009).

7) H. D. Schreiber, S. K. Kozak, P. G. Leonhard and K. K. McManus, Glastech. Ber., 60, 389-398 (1987).

8) H. D. Schreiber, S. K. Kozak, P. G. Leonhard, K. K. McManus and C. W. Schreiber, Glastech. Ber., 61, 5-11 (1988).

9) H. D. Lee, S. K. Kozak, C. W. Schreiber, D. G. Wetmore and M. W. Riethmiller, Glastech. Ber., 63, 49-60 (1990).

10) T. Asahi, S. Nakayama, Y. Miura, T. Nanba, H. Yamashita and T. Maekawa, J. Ceram. Soc. Japan, 114, 697-704 (2006).

11) T. Asahi, S. Nakayama, T. Nanba, H. Kiyono, H. Yamashita and T. Maekawa, J. Ceram. Process. Res., 9, 401-406 (2008).

12) A. A. Ahmed, T. M. El-Shamy and N. A. Sharaf, J. Non-Cryst. Solids, 33, 159-167 (1979).

13) W. J. Dell, P. J. Bray and S. Z. Xiao, J. Non-Cryst. Solids, 58, $1-16(1983)$.

14) T. Asahi, T. Ino, Y. Miura, T. Nanba and H. Yamashita, J. Ceram. Soc. Japan, 106, 150-154 (1998).

15) H. Maekawa, T. Maekawa, K. Kawamura and T. Yokokawa, J. Non-Cryst. Solids, 127, 53-64 (1991).

16) T. Nanba, M. Nishimura and Y. Miura, Geochim. Cosmochim. Acta, 68, 5103-5111 (2004).

17) T. Nanba, Y. Asano, Y. Benino, S. Sakida and Y. Miura, Phys. Chem. Glasses: Eur. J. Glass Sci. Technol. B, 50, 301-304 (2009).

18) T. Nanba, S. Sakida and Y. Miura, Proceedings of Materials Science \& Technology 2006, Materials and Systems, Vol. 1 (2006) pp. 535-544 [CD-ROM].

19) D. Chen, H. Miyoshi, H. Masui, T. Akai and T. Yazawa, J. Non-Cryst. Solids, 345-346, 104-107 (2004). 